\title{
Molecular Cloning and Characterization of an Anthocyanidin Synthase Gene in Prunus persica (L.) Batsch
}

\author{
Jiabao YE, Feng XU*, Guiyuan WANG*, Qiangwen CHEN, \\ Tingting TAO, Qiling SONG
}

\author{
College of Horticulture and Gardening, Yangtze University, Jingzhou, 434025, Hubei, China; yejiabao13@163.com; \\ xufeng198@126.com (*orrespondingauthors);guiyuanwang@163.com; chenqwx@163.com;18010872961@163.com;song70@126.com
}

\begin{abstract}
To elucidate the effect of anthocyanidin synthase (ANS) gene on anthocyanin accumulation in fruit skin of Prunus persica (L.) Batsch cv. 'Chunmei', this study cloned and characterized an ANS gene (PpANS) from peach. PpANS (GenBank accession No. KX760117) was encoded by a 1074 bp-long open reading frame (ORF) corresponding to a polypeptide consisting of 358 amino acids with a molecular mass of $40.45 \mathrm{kD}$ and an isoelectric point of 5.46. PpANS contains a conserved 2-oxoglutarate- and iron-dependent dioxygenases and non-haem dioxygenase binding regions. PpANS shared high similarities to angiosperm ANS and displayed the closest genetic relationship to Prunus domestica. Real-time PCR analysis indicated that $P p A N S$ was highly expressed in fruit skin, flesh and flowers, and peach fruit skin showed the highest transcript level of $P p A N S$. Anthocyanin accumulation analysis indicated that it was highly accumulated in fruit skin and flesh of peach. Changes in the transcript level were highly correlated with anthocyanin content in the different tissues of peach. Prokaryotic expression analysis showed PpANS that protein can be expressed correctly in E. coli, and the size of PpANS recombinant protein was consistent with its predicted size. In vitro enzyme activity assay revealed that recombinant PpANS protein could catalyze the formation the cyanidin from leucocyanidin. These results indicated that $P p A N S$ was responsible for anthocyanin accumulation in P. persica.
\end{abstract}

Keywords: anthocyanin accumulation, anthocyanidin synthase, expression profile, in vitro enzyme activity, peach

\section{Introduction}

Peach (Prunus persica (L.) Batsch) is a member of family Rosaceae. In terms of land area for production, peach is the third most cultivated fruit crop in temperate regions (Dirlewanger et al., 2002). Moreover, a peach tree offers high economic value. Candied fruit, dried fruit, and peach sauce are products that are very popular locally (Wisniewski et al., 2011). Peach fruit is a healthy food that contains nutrients, namely, amino acids, proteins, fats, sugars, essential oils, minerals, amygdalin, and vitamins, which are all essential to the body (Arndt et al., 2001; Jha et al., 2012). Improvement in fruit quality has recently become an important research field in pomology. The sugar-acid ratio is thus commonly used as a quality index, acid and sugar content and composition are major determinants of peach quality (Dirlewanger et al., 1999). External quality is mainly determined by fruit size and skin color. In fresh peach, the most important quality is skin color, which is easily perceived by consumers. Skin coloration is possibly the index that ultimately determines whether consumers will purchase a given batch of peaches. For this reason, skin color has been significantly improved in the past decades, and peach breeders have selected primarily for intense red color at early stage of maturity (Iglesias and Echeverría, 2009).

Anthocyanins, a class of flavonoids that play a major role in coloration of fruits and most flowers (Wang et al., 2013). Red coloration in plants is attributed to anthocyanin accumulation usually in skin and flesh of fruits. The degree of anthocyanin accumulation largely determines the quality of grape berries (Afifi et al., 2003; Yoshida et al., 2003). Fig. 1 shows the synthesis of anthocyanins in peach and of key precursors, including 4-coumaroyl-CoA and $3 \times$ malonyl-CoA, through the flavonoid biosynthetic pathway. Anthocyanidin synthase (ANS, EC. 1114111119) catalyzes the key synthesis reaction from leucoanthocyanidin to anthocyanidin. The following reaction will occur in the process described above, that is, oxidation, dehydration, and glycosylation of various leucoanthocyanidins produce corresponding anthocyanidins. Furthermore, glycosylation, methylation, and acylation are required to convert anthocyanin into cyanidin 3-glucosides (Holton and Cornish, 1995). 
The main determinant of anthocyanin accumulation in fruit is a genetic factor. The reference for environmental factors is required. Environmental factors (light, temperature, environmental stress, and loss of nutrient elements) can upregulate or downregulate the expression levels of structural and regulatory genes and correspondingly promote or inhibit synthesis and accumulation of anthocyanin, resulting in different colorations in leaves or flowers (Koes et al., 2005; Lepiniec et al., 2006). ANS is one of the key enzymes in anthocyanin biosynthesis. ANS involved in later phase of anthocyanin biosynthetic and dependent on 2-ketoglutate acid and $\mathrm{Fe}^{2+}$ in catalyzing conversion of colorless pigments into colored pigments in flowers (Heller et al., 1985; Koes et al., 2005). ANS is encoded by a mini-gene family in many plants. $A N S$ gene have been cloned and functionally analyzed in Theobroma cacao (Liu et al., 2013), Brassica carinata (Yan et al., 2014), Brassica juncea (Yan et al., 2011), Fructus mori (Qi et al., 2014), Punica granatum L. (Ben-Simhon et al., 2015), Malus spectabilis (Zhang et al., 2015), and Pyrus communis L. (Yang et al., 2013); however, few reports on regulation of anthocyanin accumulation by $A N S$ gene in peach fruit skin are available. In the present study, an ANS gene $(P p A N S)$ was isolated from peach fruit skin by using RT-PCR technique to determine the function of $P p A N S$ in peach fruit. We investigated the structure of the gene, as well as deduced the amino acid composition and the recombinant product of prokaryotic expression vector in $E$. coli. We identified the products of the incubation of recombinant PpANS protein with 3,4-cisleucocyanidin as substrate in vitro through high-performance liquid chromatography (HPLC). Moreover, we determined the transcript levels of $P p A N S$ and accumulation pattern of anthocyanins in roots, stems, leaves, flowers, and fruit skin and flesh of peach.

\section{Materials and Methods}

\section{Plant material}

This study used the six-year-old trees of peach cv. 'Chunmei' (P. persica) and peach rootstock cultivars of 'Flordaguard' grown in deciduous fruit tree base in the College of Horticulture and Landscape Architecture, Yangtze University, Jingzhou, Hubei Province, China. Spatial expression profile of PpANS was measured from roots, stems, leaves, flowers, and fruit flesh and skin, which were immediately frozen in liquid nitrogen and stored at $-80^{\circ} \mathrm{C}$ until further analyses.

\section{$D N A$ and $R N A$ extraction and $C D N A$ synthesis}

Different tissues of peach sample $(1 \mathrm{~g})$ were immediately pulverized in liquid nitrogen, filtered, and centrifuged at 12,000 $\times \mathrm{g}$ for $10 \mathrm{~min}$ at $4^{\circ} \mathrm{C}$. Total RNA was extracted from the roots, stems, leaves, flowers, and fruit flesh and skin of peach by using the CTAB method as described by Xu et al. (2008). Genomic DNA of the peach fruit skin was extracted by using the $C T A B$ method (Xu et al., 2014). Prior to the use of the total RNA and DNA, their purity, concentration, and quality were tested at OD260/280 absorbance ratio and by using spectrophotometer and $1 \%(\mathrm{w} / \mathrm{v})$ agarose gel electrophoresis. First-strand cDNA was synthesized using PrimeScript ${ }^{\mathrm{TM}}$ II 1st Strand cDNA Synthesis Kit (TaKaRa, Dalian, China). The reaction mixture was $20 \mu \mathrm{l}$ and consisted of Oligo dT Primer $(1 \mu \mathrm{l})$, dNTP mixture $(1 \mu \mathrm{l})$, total RNA $(8 \mu \mathrm{l}) ; 5 \times$ Primescript buffer $(4 \mu \mathrm{l})$,
RNase inhibitor $(0.5 \mu \mathrm{l})$, Prime Script RTase $(1 \mu \mathrm{l})$, and RNAfree $\mathrm{H}_{2} \mathrm{O}(4.5 \mu \mathrm{l})$. The reaction was performed at $45^{\circ} \mathrm{C}$ for 20 min followed by a reaction at $75^{\circ} \mathrm{C}$ for $15 \mathrm{~min}$.

\section{Cloning offull-length cDNA of PpANS}

The specific primer pair ANS-FP (5'ATGGTGAGCTCTGDTTCAGTGA-3') and ANS-RP (5'TCACTTGTTGAGCAAAGCTTCT-3') were designed and synthesized (Shanghai Sangon, China) based on the transcriptome sequencing data for $P$. persica. The PCR reaction conditions were as follows: $95^{\circ} \mathrm{C}$ for $3 \mathrm{~min}$ followed by 35 cycles at $95^{\circ} \mathrm{C}$ for $30 \mathrm{~s}, 56^{\circ} \mathrm{C}$ for $30 \mathrm{~s}$, and $72{ }^{\circ} \mathrm{C}$ for $90 \mathrm{~s}$ with an extension at $72{ }^{\circ} \mathrm{C}$ for $10 \mathrm{~min}$ (Li et al., 2015). The amplified products were analyzed by $1 \%$ gel electrophoresis, purified using an AxyPrep DNA Extraction Kit, cloned into pMD19-T vector (Shanghai Sangon, China), and then sequenced (Flugge and Gao, 2005).

\section{Bioinformatics and molecular evolution analyses}

BioEdit 7.0 and MEGA 6.0 were used to construct a phylogenetic tree through the neighbor-joining method and to perform multiple alignment analysis of the amino acid sequences of ANS, respectively (Kumar et al., 2004; Tamura et al., 2007). Sequence homology searches and analysis were implemented using online bioinformatics tools (bttp://www.ncbi.nlm.nih.gov). Oligo 6 software was utilized to design the primers used in the experiment. The online tool ExPASy-ProtParam (www.expasy.

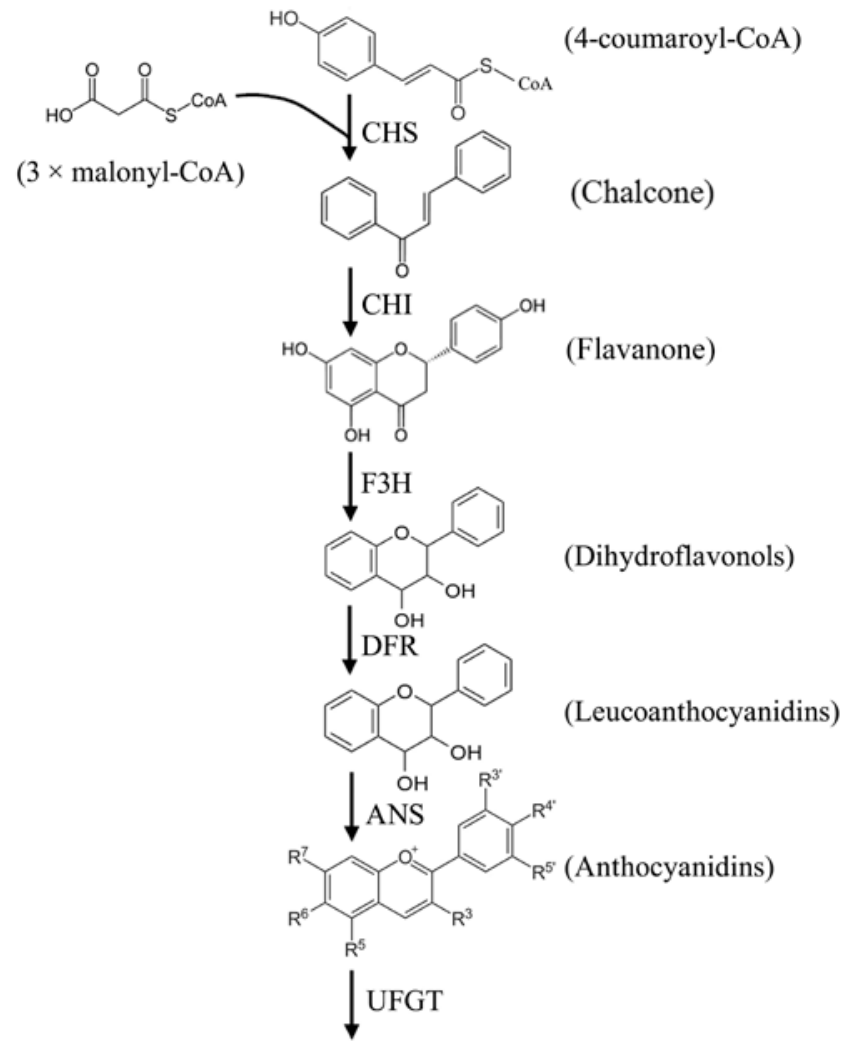

\section{Anthocyanins}

Fig. 1. Anthocyanin biosynthesis pathway in peach. CHS chalcone synthase, $\mathrm{CHI}$ chalcone isomerase, $\mathrm{F} 3 \mathrm{H}$ flavanone-3hydroxylase, DFR dihydroflavonol-4-reductase, ANS anthocyanidin synthase, UFGT glucoseflavonoid3-o-glucosyl transferase 
30

org/tools/protparam.html) was used to deduce the molecular weight and isoelectric point (pI) of proteins (Guex et al., 1997; Emanuelsson et al., 2000).

\section{Quantitative real-time PCR ( $q R T-P C R)$ analysis}

Roots, stems, leaves, flowers, and fruit flesh and skin were sampled from peach trees. Total RNA was isolated from each sample by using the CTAB method, first-strand $\mathrm{CDNA}$ was synthesized using a PrimeScriptTM RT Reagent Kit (Dalian TaKaRa, China). The resulting cDNA mixtures were used to prepare the templates for qRT-PCR. The qRT-PCR product was measured using a Bio-Rad iQ5 thermal cycler with SYBR Premix Ex Taqu II Kit (Dalian TaKaRa, China) according to the manufacturer's protocol. Expression was normalized to a gene from peach (Pp18S), the reference genes and primer sequences for the qRT-PCR are Pp18S-F (5'- CGGCCCATTCGA GATAACAC - $3^{\prime}$ ) and Pp18S-R (5'- AGACTTATGGGAG CCGATCC - $3^{\prime}$ ); ANS-RTF (5'- AACGAAAATGTGAGA GAGAG - $3^{\prime}$ ) and ANS-RTR (5'- GCATTGTTTGCAA GCTTGCT $-3^{\prime}$ ) were designed and synthesized by Shanghai Sangon (China). Original data were analyzed by Light Cycler software and real-time PCR data on ANS gene were calculated using the $2^{-\Delta \Delta \mathrm{CT}}$ method as described by Livak and Schmittgen (2001).

\section{Measurement of anthocyanin content}

Anthocyanin content in the tissues of $P$. persica was assayed according to the method of Connor et al. (2002). One gram sample were frozen with liquid nitrogen, ground into a fine powder and extracted using $0.5 \% \mathrm{HCl}$ in methanol solution with shaking at $4{ }^{\circ} \mathrm{C}$ for $6 \mathrm{~h}$. The extracts were centrifuged at $8,000 \times \mathrm{g}$ for $20 \mathrm{~min}$; the supernatant was transferred into a sterile tube. Absorbance was measured at $530 \mathrm{~nm}$ and expressed as $\mathrm{mg}$ of cyanidin 3-O-glucoside equivalents per gram fresh weight (FW) of tissue.

\section{PpANS expression in E. coli}

The recombinant product of the prokaryotic expression vector pET32a-PpANS was constructed using the forward primer ANS-YF (5'- GCCATGGCTGATATCGATCC ATGGTGAGCTCTGATTCAGTGA - $3^{\prime}$ ) and the reverse primer ANS-YR (5'- CTCGAGTGCGGCCGCAAGCT TTCACTTGTTGAGCAAAGCTTCT $-3^{\prime}$ ); the underlined portion of the forward and reverse primers are the sites for enzymatic digestion, in which GGATCC was digested by Bam H I and AAGCTT was digested by Hind III. The 1074 bplong ORF of the amplified cDNA fragments was doubly digested by Bam H I and Hind III, and pET32a vector (Thermo Fisher, USA) was digested with the same restriction enzymes. The target gene of $P$ PANS was subsequently inserted into the pET32a vector, generating the recombinant plasmid pET32aPpANS.

The recombinant plasmid of pET32a-PpANS was transformed into $E$. coli BL21. The transformants were incubated overnight in $20 \mathrm{ml}$ of LB liquid medium containing $50 \mu \mathrm{g} / \mathrm{ml}$ of ampicillin at $37^{\circ} \mathrm{C}$ with shaking at $200 \mathrm{rpm}$. Overnight cultures were diluted by 100 -fold in LB medium, placed into $50 \mathrm{mg} / \mathrm{ml}$ ampicillin, and cultivated at $37^{\circ} \mathrm{C}$ for $4 \mathrm{~h}$ until an $\mathrm{A} 600$ of $0.5-0.6$ was reached. The cultures were induced with $1.0 \mathrm{mM}$ isopropyl- $\beta$-D-d-thiogalactoside (IPTG) and incubated at $30{ }^{\circ} \mathrm{C}$ with shaking at $200 \mathrm{rpm}$ for $4 \mathrm{~h}$. The suspension was incubated in $200 \mu \mathrm{l}$ of buffer solution at $100^{\circ} \mathrm{C}$ for $5 \mathrm{~min}$ and centrifuged at 12,000 $\times \mathrm{g}$ for $15 \mathrm{~min}$ (Zhu et al., 2014). Experimental result was analyzed by sodium dodecyl sulfate polyacrylamide gel electrophoresis (SDS-PAGE) by using $12 \%$ polyacrylamide separation gel and 5\% stacking gel as described by Bradford (1976). The recombinant PpANS protein was purified using View-IP ${ }^{\mathrm{m} x}$ Calmodulin Red Separopore (Agarose) 4B-CL (BioWORD Separopore) and then used for in vitro enzyme assay.

\section{Assay of PpANSactivity}

The enzymatic activity of recombinant PpANS was assayed using the method described by Pang et al. (2007) with slight modification. ANS activity was measured in a final volume of $500 \mu \mathrm{l} \mathrm{containing} 8 \mathrm{mmol} / \mathrm{l}$ sodium ascorbate, $400 \mathrm{mmol} / \mathrm{l}$ sodium chloride $(\mathrm{NaCl}), 2 \mathrm{mmol} / \mathrm{l}$ 2-oxoglutaric acid, 20 $\mathrm{mmol} / \mathrm{l}$ maltose, $10 \mathrm{mmol} / \mathrm{l}$ dithiothreitol (DTT), $1 \mathrm{mmol} / \mathrm{L}$ $\mathrm{FeSO}_{4} 1 \mu \mathrm{mol} / \mathrm{L}$ 3,4-cis-leucocyanidin, $40 \mathrm{mmol} / \mathrm{L} \mathrm{KPi}$ buffer $(\mathrm{pH} 7.5)$, and $100 \mu \mathrm{g}$ of purified PpANS protein. After incubation at $30{ }^{\circ} \mathrm{C}$ for $1 \mathrm{~h}$, the reaction was terminated by addition of $8 \mu \mathrm{l}$ of $18 \%$ hydrochloric acid $(\mathrm{HCl})$ and $40 \mu \mathrm{l}$ of methyl alcohol (Tanner and Kristiansen, 1993). The sample aqua was centrifuged at $12,000 \times \mathrm{g}$ for $5 \mathrm{~min}$, and then the supernatant was passed through a $0.22 \mu \mathrm{m}$ syringe filter according to the method described by Lockhart and Winzeler (2000). The enzymatic products were analyzed using an Agilent 1100 HPLC (Agilent Technology Co., Ltd. USA) with XDBC18 reverse phase column $(25 \mathrm{~cm} \times 4.6 \mathrm{~mm} \times 25 \mu \mathrm{m}$ ) (Agilent ZORBAX Eclipse, USA). The binary mobile phase used in the experiment consisted of $1 \%$ phosphoric acid and 50\% methyl cyanide. Flow rate was maintained at $1 \mathrm{ml} / \mathrm{min}$, and experimental data were measured at $530 \mathrm{~nm}$. Cyanidin concentration was calculated based on a 3,4-cis-leucocyanidin standard (Sigma-Aldrich, USA). Empty pET32a vector from induced BL21 was used as control.

\section{Results}

\section{Cloning of cDNA of P $p A N S$}

Based on the sequences of the $5^{\prime}$ - and $3^{\prime}$-RACE products, full-length cDNA was deduced and amplified through PCR by using the primer pair ANS-FP and ANS-RP. The cloned fulllength ORF of the PpANS was 1074 bp long. The G/C content in PpANS nucleotide sequence was $49.16 \%$ and encodes 358 amino acid with a molecular mass of $40.45 \mathrm{kD}$ and a $\mathrm{pI}$ of 5.46. The nucleotide sequence of PpANS was highly similar to that of the $A N S$ of other plants (Table 1). The nucleotide sequence of $P$ PANS was 98\%, 98\%, 97\%, 97\%, $97 \%, 97 \%, 97 \%, 89 \%, 91 \%$, and $91 \%$ identical to that of the ANS genes of $P$. cerasifera, P. salicina var. cordata, P. avium, $P$. domestica, P. cerasus, Pyrus communis, Malus domestica, Rosa rugosa, Pyrus $x$ bretschneideri, and Pyrus pyrifolia, respectively, implying that $P p A N S$ is a member of the ANS gene family. Furthermore, the homology of ANS gene sequence among different species suggested that ANS was strongly conserved during molecular evolution.

\section{Characterization of the deduced PpANS protein}

Sequence comparison through BLASTP searching (http://www.ncbi.nih.gov) showed that PpANS is highly homologous to other ANS, and multi-alignment of amino acid 
Table 1. Nucleotide sequence of PPANS similarity to the ANS genes of other plant species

\begin{tabular}{lccc}
\hline \multicolumn{1}{c}{ Species } & $\begin{array}{c}\text { GenBank } \\
\text { Accession No. }\end{array}$ & Identity (\%) & E-value \\
\hline Prunus cerasifera & AKV89246.1 & 98 & 0.0 \\
\hline Prunus salicina var. cordata & AEN19292.1 & 98 & 0.0 \\
Prunus avium & AEO79983.1 & 97 & 0.0 \\
Prunus domestica & AHZ30597.1 & 97 & 0.0 \\
Prunus cerasus & AJO67980.1 & 97 & 0.0 \\
Pyrus communis & AGL50919.1 & 92 & 0.0 \\
Malus domestica & AAD26205.1 & 92 & 0.0 \\
Rosa rugosa & AKT74337.1 & 89 & 0.0 \\
Pyrus $\times$ bretscbneideri & AJD00703.1 & 91 & 0.0 \\
Pyrus pyrifolia & ADP09379.1 & 91 & 0.0 \\
\hline
\end{tabular}

sequences (Fig. 2) showed that PpANS display high identities to P. salicina var. cordata (98\%, AEN19292.1), P. avium (97\%, AEO79983.1), P. domestica (97\%, AHZ30597.1), P. cerasus (97\%, AJO67980.1), Pyrus $\times$ bretschneideri (92\%, AJD00703.1), M. domestica (92\%, AAD26205.1), $R$. rugosa (89\%, AKT74337.1), Nekemias grossedentata (85\%, AGO02175.1), and Vitis vinifera (84\%, ABV82967.1). Conserved domain searching (http://www.ncbi.nih.gov) revealed that PpANS belongs to the 2-oxoglutarate- and irondependent dioxygenases (2OG- $\mathrm{Fe}^{2+}-\mathrm{OXY}$ ) and non-haem dioxygenase (DIOX-N) superfamilies, which are characterized by the presence of the conserved domains $2 \mathrm{OG}-\mathrm{Fe}^{2+}-\mathrm{OXY}$ and DIOX-N, respectively. All of these findings indicate that PpANS is a member of the ANS family.

\section{Analysis of the molecular evolution of PpANS}

A phylogenetic tree was constructed using BioEdit 7.0 and MEGA 6.0 software to further explore the evolutionary relationships among PpANS and other proteins involved in anthocyanidin biosynthesis in plants. Phylogenetic analysis (Fig. 3) indicated that ANS genes are clearly divided into five distinct families, namely, Rosaceae, Vitaceae, Paeoniexpertae, Convolvulaceae, and Solanaceae; in addition, all of these families descended from a common progenitor. PpANS is closely related to PcLDOX (AKV89246) and clustered into a subgroup that includes PaANS (AEO79983), PcANS (ABB70119), PbANS (AJD00703), and PsANS (AMH93692), which are found in plants that also belong to Rosaceae. PpANS is less closely related to IpANS (ABW69684), IbANS (BAA75305), and IhANS (ACS71531), which are found in members of Convolvulaceae, and to StANS (AEJ90548), SmANS (ACJ02088), IcANS (AIY22762), LrANS (AHH55331), ScANS (AEJ90547), and ScANS (AEJ90547), which are found in members of Solanaceae.

Expression profile of PDANS and Anthocyanin content in different tissues

The expression pattern of $P p A N S$ in different tissues of $P$. persica was examined by real-time PCR. Total RNA was extracted from roots, stems, leaves, flowers, and fruit flesh and skin. As shown in Fig. 4A, $P p A N S$ was expressed constitutively in most plant organs but most highly expressed in fruit skin and moderately expressed in fruit flesh. By contrast, $P p A N S$ was weakly expressed in flowers, and the lowest expression level was
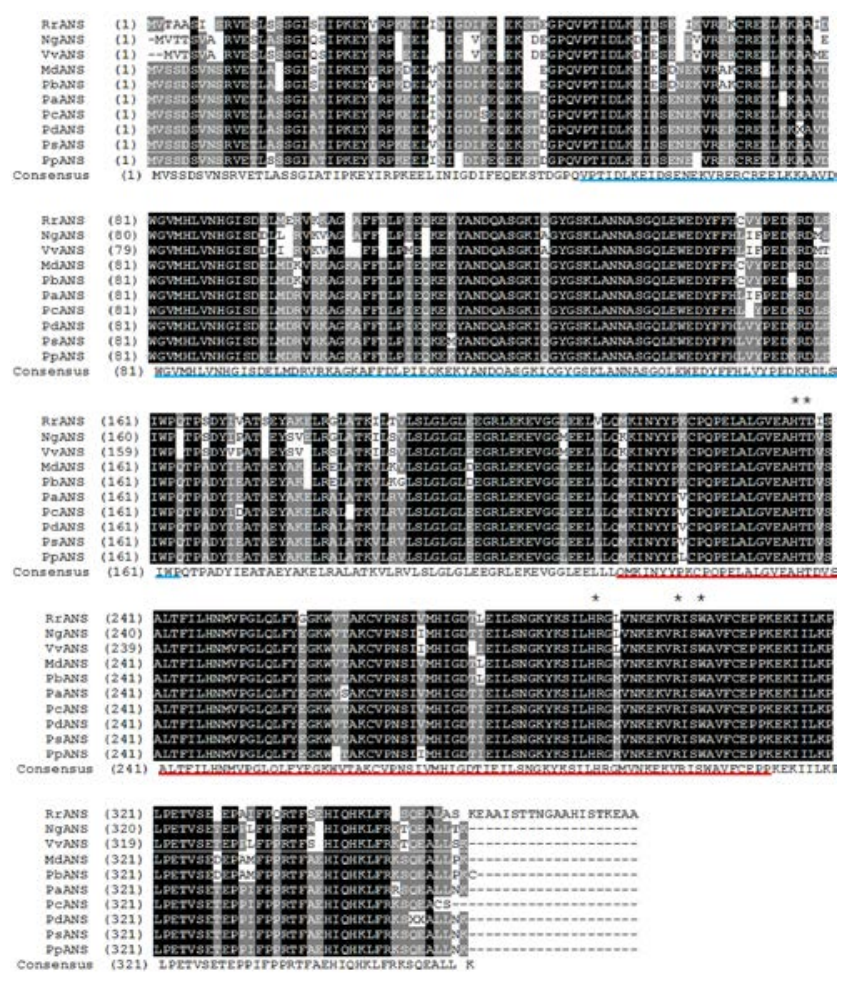

Fig. 2. Multiple alignment of PpANS with the anthocyanin synthesis in other plants. PpANS, Prunus persica; RrANS, AKT74337, Rosa rugosa; NgANS, AGO02175, Nekemias grossedentata; PbANS, AJD00703, Pyrus $\times$ bretschneideri; MdANS, AAD26205, Malus domestica; VvANS ABV82967, Vitis vinifera; PsANS, AEN19292, Prunus salicina var. cordata; PaANS, AEO79983, Prunus avium; PdANS, AHZ30597, Prunus domestica; and PcANS, AJO67980, Prunus cerasus. Alignment of some plant anthocyanidin synthase sequences available on GenBank. Asterisks indicate the conserved amino acid residues for ligating ferrous iron (HXD) and participating in 2-oxoglutarate binding (RXS). The 2oxoglutarate-and iron-dependent dioxygenases conserved domain was underlined of red colour. Identical amino acids are indicated in white foreground and black background; conserve damino acids are indicated in black foreground and light gray background; block of similar amino acids are indicated in white foreground and gray background; nonsimilar amino acids are indicated with black foreground and white background

observed in leaves. The stems and roots of $P$. persica did not show detectable $P p A N S$ transcripts.

Fig. $4 \mathrm{~B}$ shows the anthocyanin concentration of roots, stems, leaves, flowers, and fruit skin and flesh. The anthocyanins were accumulated abundantly in fruit skin, followed in the fruit flesh and flowers, and were not detected in roots. The anthocyanin content showed a good correlation with transcript level of $P p A N S$ in different tissues of $P$. persica. These data suggests that the expression of $P p A N S$ gene is one of the critical factors which determine the anthocyaninpigmentation pattern in $P$. persica. 
32

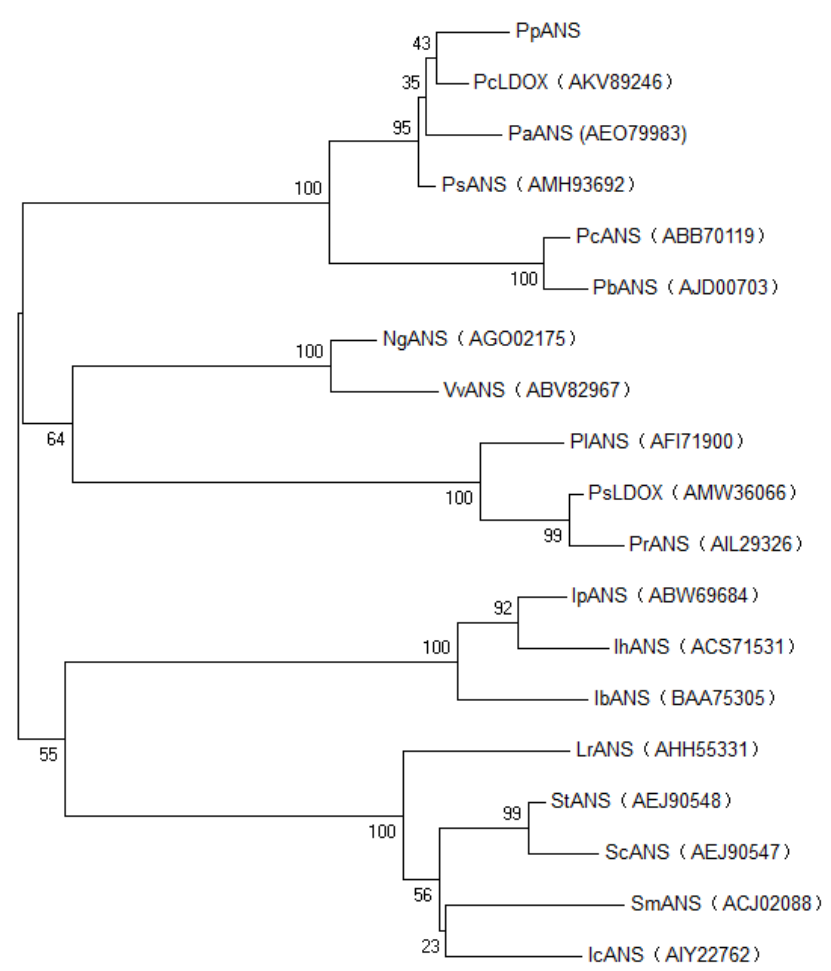

Fig. 3. Phylogenetic tree of ANS amino acid sequences from Prunus persica and other plant species generated by MEGA 6.0. The numbers using the neighbor-joining method and 1000 bootstrap replicates. The tree was built using the following ANS sequences: Prunus cerasifera, PcLDOX, AKV89246; Prunus avium, PaANS, AEO79983; Pyrus communis, PcANS, ABB70119; Pyrus $\times$ bretschneideri, PbANS, AJD00703; Prunus salicina, PsANS, AMH93692; Nekemias grossedentata, NgANS, AGO02175; Vitis vinifera, VvANS, ABV82967; Paeonia suffruticosa, PsLDOX, AMW36066; Paeonia lactiflora, PIANS, AFI71900; Solanum tuberosum, StANS, AEJ90548; Paeonia rockii, PrANS, AIL29326; Ipomoea purpurea, IpANS, ABW69684; Solanum melongena, SmANS, ACJ02088; Iochroma cyaneum, IcANS, AIY22762; Lycium ruthenicum, LrANS, AHH55331; Ipomoea horsfalliae, IhANS, ACS71531; Solanum cardiophyllum, ScANS, AEJ90547; and Ipomoea batatas, IbANS, BAA75305

\section{Expression and assay of recombinant $P$ PANS}

To induce PpANS expression in E. coli BL21 cells, we cloned the coding region of PpANS into pET32a, yielding pET32a-PpANS. The constructed expression vector was checked for in-frame fusion through restriction enzyme digestion (HindIII and Bam HI) and DNA sequencing. Expression of the recombinant protein containing the 1074 bp-long ORF of PpANS was induced for $3 \mathrm{~h}$ with $0.5 \mathrm{mmol} / \mathrm{l}$ IPTG under stirring in the early log-phase cultures of positive clones; $E$. coli cells were subsequently recovered through centrifugation and lysed via a traditional physical-chemical process. The expected molecular mass of pET32a-PpANS protein was $40.45 \mathrm{kDa}$. SDS-PAGE profile revealed a clear
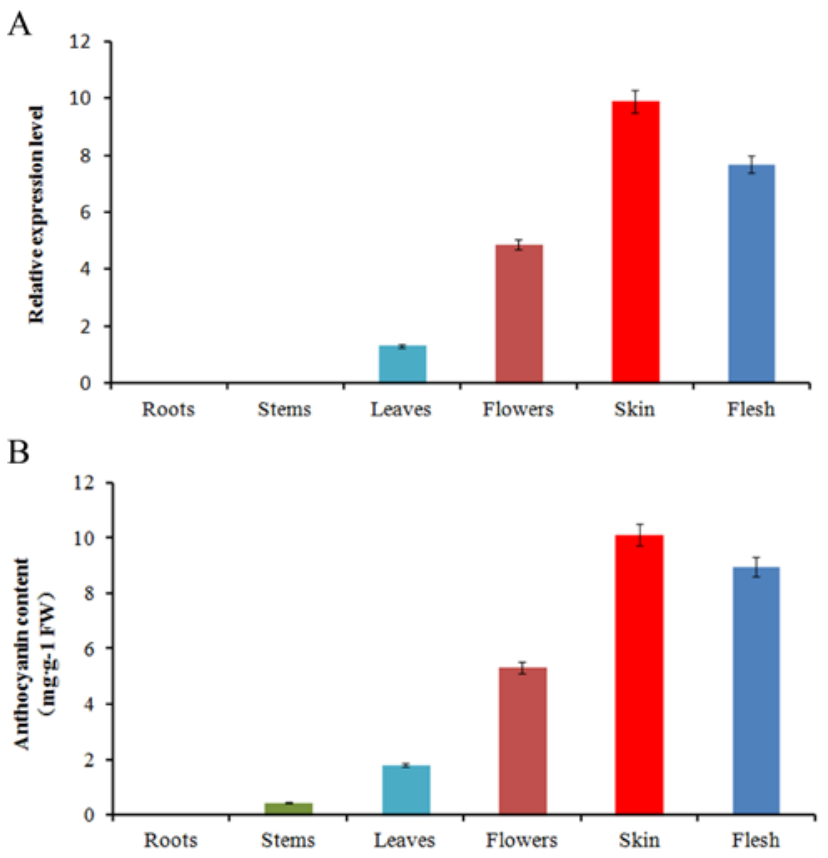

Fig. 4. Expression levels of PpANS gene (A) and anthocyanin content (B) in different tissues of Prunus persica. Analysis of expression of $P p A N S$ and anthocyanin content in roots, stems, leaves, flowers, skin, and flesh. Data are the mean \pm SD of three replicates

protein band of 39.2-66.2 $\mathrm{kDa}$ (Lane 3, Fig. 5), and this band was not observed in other control, consistent with the predicted molecular mass of the translated sequences. These results suggested that recombinant PpANS proteins were expressed as inclusion bodies in $E$. coli cells.

The activity of the purified recombinant PpANS protein was assayed by using 3,4-cis-leucocyanidin as substrate in the presence of ferrous iron and 2-oxoglutaric acid. As shown in Figs. 6A and 6C, recombinant PpANS was detected by HPLC at $530 \mathrm{~nm}$, and its identity confirmed as cyanidin by comparison of retention time and UV/Vis spectrum with those of authentic standards. By contrast, the empty vector control for the incubations with protein extract showed that no 3,4-cis-leucocyanidin was converted into cyanidin (Fig. 6B).

\section{Discussion}

In plants, $A N S$ gene plays an important role in regular developmental processes, as well as involved in adaptation to all environmental conditions. Many ANS genes participating in anthocyanin biosynthesis have been cloned from plants (Reddy et al., 2007); however, few reports on ANS proteins in $P$. persica are available. The present study reports on one $A N S$ gene $(P p A N S)$ isolated from the fruit skin of $P$. persica. Amino acid sequence analysis showed that PpANS protein contains a conserved structural domain consisting of 2-oxoglutarate and combination sites for iron ions and belonging to the 2OG$\mathrm{Fe}^{2+}-\mathrm{OXY}$ superfamily. This structure is composed of a conserved 2-oxoglutarate- and $\mathrm{Fe}^{2+}$-dependent oxidation region, containing conserved arginine related to the combination of 2-oxoglutarate and the $\mathrm{Fe}^{2+}$ combinationrelated amino acid residues as both conserved histidine and aspartate. The structural characteristic of $A N S$ gene is 


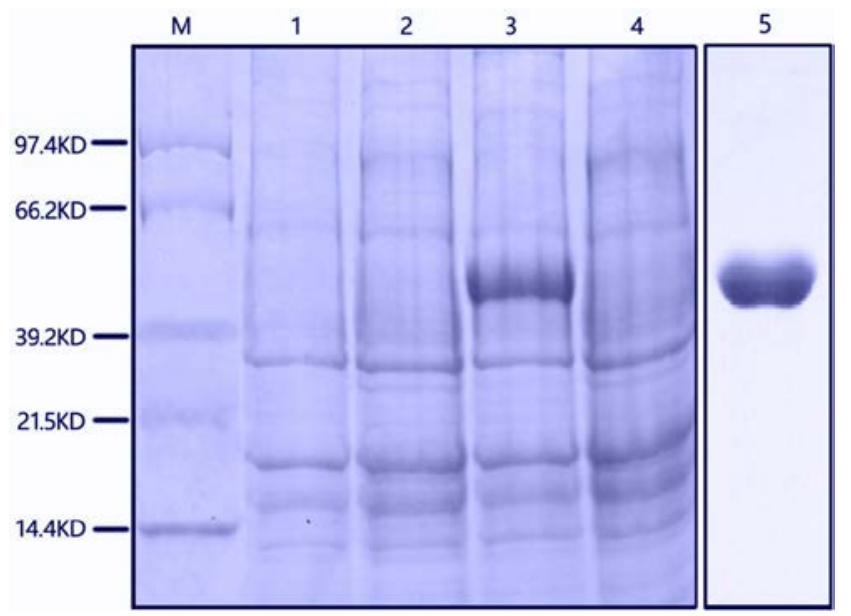

Fig. 5. SDS-PAGE electrophoresis of PpANS expressed in $E$. coli BL21. After IPTG induction, E. coli BL21cells containing pET32a-PpANS were grown at $30{ }^{\circ} \mathrm{C}$ for $6 \mathrm{~h}$. Supernatants and pellets were examined by SDS-PAGE analysis followed by Coomassie Brilliant Blue R250 (CBB) staining. Lane M protein molecular markers; Lane 1 - Proteins of total cells containing pET32a after $4 \mathrm{~h}$ induction by IPTG; Lane 2 Proteins of total cells containing pET32a without IPTG induction; Lane 3 - Proteins of total cells containing pET32aPpANS after 4 h induction by IPTG; Lane 4 - Proteins of total cells containing pET32a-PpANS without IPTG induction. Lane 5 - Purified recombinant PpANS protein used for enzyme activity assay

obviously consistent with those of the dioxygenase enzyme family, which was speculated to catalyze the formation of anthocyanidins and flavonoids in plants (Rosati et al., 1999). These typical features are consistent with those of $A N S$ gene of other plants. The results of the sequence analysis suggest that $P p A N S$ facilitates the catalytic synthesis of anthocyanins. Multiple alignment of the amino acid sequence of PpANS with that of $P$. cerasifera, $P$. avium, and $P$. salicina showed that PpANS shared high identity with the homologous member of Rosaceae (Fig. 3). The evolution of PpANS resulted in distinct characteristics at the genus and species levels. Purified recombinant PpANS protein showed that PpANS can catalyze conversion of cyanidin into leucocyanidin (Fig. 6), confirming its participation in anthocyanidin biosynthetic pathway. Based on the results of the structural, functional, and sequence analyses of $P p A N S$, PpANS is speculated to play the role of multifunctional dioxygenases and mediates different dioxygenase activities in anthocyanidin biosynthetic pathway in $P$. persica, consistent with previous studies in ginkgo (Xu et al., 2008).

The expression levels of $P p A N S$ in different tissues of peach trees varied (Fig. 4A). PpANS expression was higher in fruit skin and flesh, and flowers, and this phenomenon is possibly related to anthocyanin synthesis. Scientific research shows that these changes in transcript levels and anthocyanin accumulation at different developmental stages in the skins of peach were positively related to each other (Tsuda et al., 2004). $P$ PANS is possibly involved in molecular regulations of coloration in peach flowers and fruits, in which large amounts
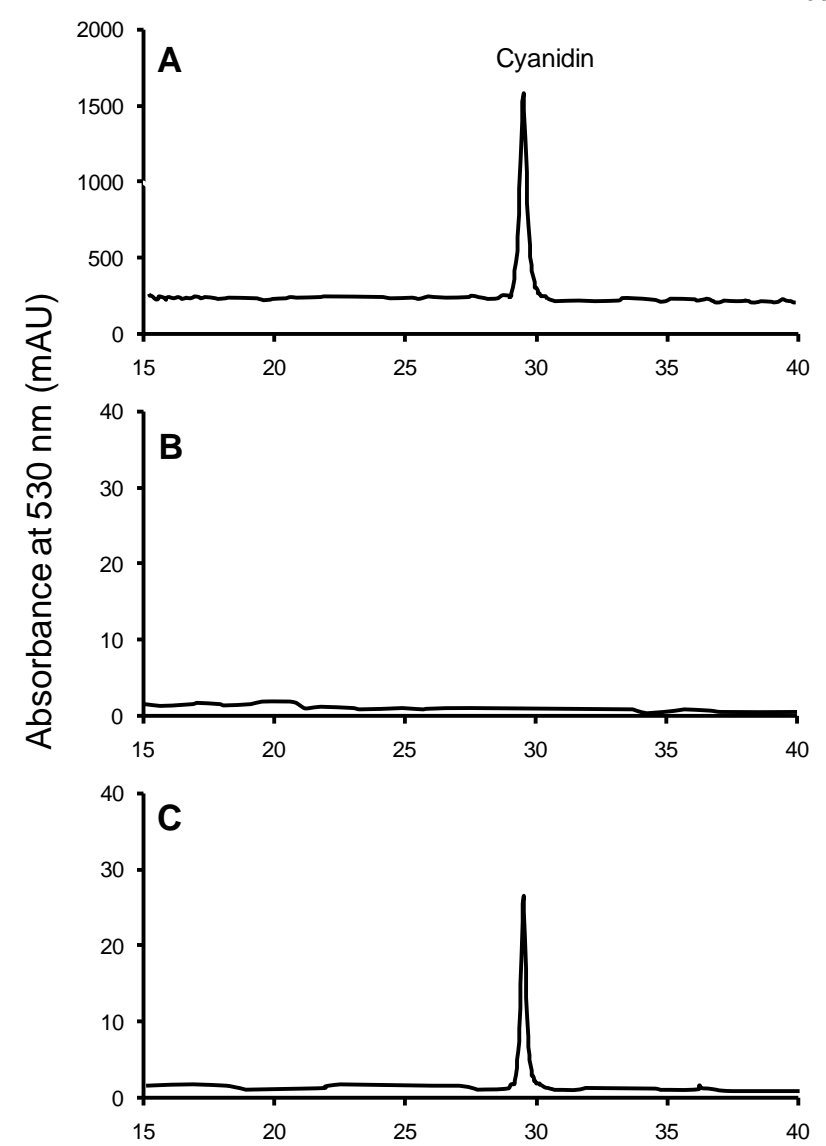

Fig. 6. HPLC analysis of the products from incubation of recombinant PpANS protein with 3, 4-cis-leucocyanidin as substrate. (A) HPLC analysis of an authentic standard of cyanidin; (B) Product form incubation of 3, 4-cisleucocyanidin with crude protein extract from vector control; (C) Product from incubation of 3, 4-cis-leucocyanidin with purified recombinant $P p A N S$ by UV absorption

of $P p A N S$ expression are required. This finding is consistent with that in grapes as reported by Wang et al. (2010). However, no $P_{p} A N S$ expression was detected in stem. This result may be attributed to the use of young parts as experimental materials; these parts were still in the phase of leucoanthocyanidin synthesis, and PpANS remains unexpressed. These data showed that the expression levels of $P p A N S$, the contents of anthocyanin were significantly consistency (Fig. 4). Our recently work showed that the dynamic changes of anthocyanin content in peach peel were similar to the changes of $A N S$ gene expression levels (Ye et al., 2017). The changes in abundance of $P p A N S$ expression in different tissues of peach were synergistic with the changes in anthocyanin content, suggesting that $P p A N S$ is a key factor in anthocyanin synthesis in peach. Anthocyanin content changed with enzyme activity, which was controlled by abundance of ANS gene expression. Aharoni et al. (2001) inhibited ANS gene expression in strawberries; consequently, anthocyanin accumulation significantly decreased and then the color of corolla changed from pink to white. This study showed that the catalytic process induced by ANS in the transition from colorless anthocyanin into colored anthocyanin was one of the 
34 most important factors in red coloration in peach. The expression of anthocyanin biosynthetic genes (ANS) dramatically decreased in peach leaves, resulting in a significant decrease of anthocyanin accumulation (Zhou et al., 2013). Nakamura et al. (2006) inhibited ANS gene expression in Torenia fournieri by using RNAi and found that anthocyanin content in $T$. fournieri strains was greatly reduced. ANS gene was mainly regulated by effect of various signals on transcription, thereby influencing the anthocyanin synthesis in plants; this finding is consistent with the results for Litchi chinensis as reported by Wei et al. (2011). To sum up, ANS gene exerts a regulatory function in anthocyanin synthesis.

In anthocyanin biosynthetic pathway of plant, enzymes involved in anthocyanin synthesis can catalyze conversion of colorless anthocyanin into colored anthocyanin, and the byproducts further demonstrate coupled reaction with 3-Oglucose transferase, and the coupling product is subsequently sent to the vacuole where colored 3-O-glycosylated anthocyanins form; hence, anthocyanin plays a very important role in color formation in plants (Nakajima et al., 2001). All the biosynthetic pathway genes, including $A N S$, showed significantly higher level of expression in red leaves than in green leaves (Zhou et al., 2014). ANS act as a key enzyme necessary in anthocyanin synthesis and in the metabolic pathways of anthocyanin in peach. However, little is known about the links between phenotype and genotype in coloration of flowers or fruits. In this study, the PpANS gene that expresses the enzyme for anthocyanin synthesis was obtained from peach fruit skin, and prokaryotic expression of its protein was performed in vitro to obtain purified recombinant protein showing clear target bands. This study found that in vitro expression of PpANS is possible. In further study, gene expression carriers for $A N S$ will be established for genetic transformation and function validation to further investigate the mechanism of the role of PpANS in anthocyanin metabolism in peach skin and ultimately lay the foundation for molecular modification of peach fruit colors.

\section{Conclusions}

This study isolated and characterized $P p A N S$ from $P$. persica, and the results suggested that post-transcriptional RNA processing controls color changes in fruit skin. Although we have not yet sufficiently demonstrated the function of $P_{p} A N S$, the higher transcript levels of $P p A N S$ in fruit skin and flesh than in other plant tissues indicate that PpANS protein plays an active role in fruit coloration. Further characterization of the specific gene necessary to establish a color development model for $P p A N S$ in $P$. persica, as well as identification of specific means to improve fruit coloring by utilizing molecular breeding in P.persica, is a significant endeavor in future research.

\section{Acknowledgements}

This work was supported by National Natural Science Foundation of China (No. 31300574).

\section{References}

Aharoni A, De Vos C, Wein M (2001). The strawberry FaMYB1 transcription factor suppresses anthocyanin and flavonol accumulation in transgenic tobacco. Plant Journal 28(3):319-332.
Afifi M, El-Kereamy A, Legrand V, Chervin C, Monje MC, Nepveu F, Roustan JP (2003). Control of anthocyanin biosynthesis pathway gene expression by eutypine, a toxin from Eutypa lata, in grape cell tissue cultures. Journal of Plant Physiology 160(8):971-975.

Arndt SK, Clifford SC, Wanek W, Jones HG, Popp M (2001). Physiological and morphological adaptations of the fruit tree Ziziphus rotundifolia in response to progressive drought stress. Tree Physiology 21(11):705-715.

Ben-Simhon Z, Judeinstein S, Trainin T, Harel-Beja R, Bar-Yaakov I, Borochov-Neori H, Holland D (2015). A "White" anthocyanin-less pomegranate (Punica granatum L.) caused by an insertion in the coding region of the leucoanthocyanidin dioxygenase (LDOX; ANS) gene. PloSOne 10(11):e0142777.

Bradford MM(1976). A rapid and sensitive method for the quantitation of microgram quantities of protein utilizing the principle of protein-dye binding. Analytical Biochemistry 72(1-2):248-254.

Connor AM, Luby JJ, Tong CB, Finn CE, HancockJF (2002). Genotypic and environmental variation in antioxidant activity, total phenolic content, andanthocyanin content among blueberry cultivars. Journal of the American Society for Horticultural Science 127(1):89-97.

Dirlewanger E, Cosson P, Tavaud M, Aranzana M, Poizat C, Zanetto A, Laigret F (2002). Development of microsatellite markers in peach [Prunus persica (L.) Batsch] and their use in genetic diversity analysis in peach and sweet cherry (Prunus avium L.). Theoretical and Applied Genetics 105(1):127-138.

Dirlewanger E, Moing A, Rothan C, Svanella L, Pronier V, Guye A, Monet $\mathrm{R}$ (1999). Mapping QTLs controlling fruit quality in peach (Prunus persica (L.) Batsch). Theoretical and Applied Genetics 98(1):18-31.

Emanuelsson O, Nielsen H, Brunak S, Von Heijne G (2000). Predicting subcellular localization of proteins based on their $\mathrm{N}$-terminal amino acid sequence.Journal of Molecular Biology 300(4):1005-1016.

Flugge UI, Gao W (2005). Transport of isoprenoid intermediates across chloroplast envelope membranes. Plant Biology 7:91-97.

Guex N, Peitsch MC (1997). SWISS-MODEL and the Swiss-Pdb Viewer: an environment for comparative protein modeling. Electrophoresis 18:2714-2723.

Heller W, Forkmann G, Britsch L, Grisebach H (1985). Enzymatic reduction of (+)-dihydroflavonols to flavan-3,4-cis-diols with flower extracts from Matthiola incana and its role in anthocyanin biosynthesis. Planta 165:284287.

Holton TA, Cornish EC (1995). Genetics and biochemistry of anthocyanin biosynthesis. Plant Cell 7(7):1071.

Iglesias I, Echeverría G (2009). Differential effect of cultivar and harvest date on nectarine colour, quality and consumer acceptance. Scientia Horticulturae 120(1):41-50.

Jha B, Lal S, Tiwari V, Yadav SK, Agarwal PK (2012). The SbASR-1 gene cloned from an extreme halophyte Salicornia brachiata enhances salt tolerance in transgenic tobacco. Molecular Biotechnology 14:782-792.

Koes R, Verweij W, Quattrocchio F (2005). Flavonoids: a colorful model for the regulat ion and evolut ion of biochemical pathways. Trends Plant Science 10:236-242.

Kumar S, Tamura K, Nei M (2004). MEGA3: Integrated software for molecular evolutionary genetics analysis and sequence alignment. Brief 
in Bioinformatics 5:150-163.

Lepiniec L, Debeaujon I, Routaboul JM (2006). Genetics and biochemistry of seed flavonoids. Annual Review of Plant Biology 57:405-430.

Li XG, Wang J, Yu ZY (2015). Cloning of an anthocyanidin synthase gene homolog from blackcurrant (Ribes nigrum L.) and its expression at different fruit stages. Genetics and Molecular Research 14(1):27262734 .

Liu Y, Shi Z, Maximova S, Payne MJ, Guiltinan MJ (2013). Proanthocyanidin synthesis in Theobroma cacao: genes encoding anthocyanidin synthase, anthocyanidin reductase, and leucoanthocyanidin reductase. BMC Plant Biology 13(1):202.

Livak KJ, Schmittgen TD (2001). Analysis of relative gene expression data using real-time quantitative PCR and the $2^{-\triangle \triangle C T}$ method. Methods 25(4):402-408.

Lockhart DJ, Winzeler EA (2000). Genomics, gene expression and DNA arrays. Nature 405(6788): 827-836.

Nakajima J, Tanaka Y, Yamazaki M, Saito K (2001). Reaction mechanism from leucoanthocyanidin to anthocyanidin 3-gucoside, a key reaction for coloring in anthocyanin biosynthesis. Journal of Biological Chemistry 276:25797-25803.

Nakamura N, Fukuchi MM, Miyazaki K (2006). RNAi suppression of the anthocyanidin synthase gene in Torenia bybrida yields white flowers with higher frequency and better stability than antisense and sense suppression. Plant Biotechnology23(1):13-17.

Pang Y, Peel GJ, Wright E, Wang Z, Dixon RA (2007). Early steps in proanthocyanidin biosynthesis in the model legume Medicago truncatula. Plant Physiology 145(3):601-615.

Qi X, Shuai Q, Chen H, Fan L, Zeng Q, He N (2014). Cloning and expression analyses of the anthocyanin biosynthetic genes in mulberry plants. Molecular Genetics and Genomics 289(5):783-793.

Reddy AM, Reddy VS, Scheffler BE, Wienand U, Reddy AR (2007). Novel trangenic rice overexpression anthocyanidin synthase accumulates a mixture of flavonoids leading to an increased antioxidant potential. MetabolicEngineering 9:95-111.

Rosati C, Cadic A, Duron M, Ingouff M, Simoneau P (1999). Molecular characterization of the anthocyanidin synthase gene in Forsythia $\times$ intermedia reveals organ-specific expression during flower development. PlantScience 149(1):73-79.

Tamura K, J Dudley, M Nei, S Kumar (2007). MEGA4: Molecular Evolutionary Genetics Analysis (MEGA) Software Version 4.0. Molecular Biology and Evolution 24:1596-1599.

Tanner GJ, Kristiansen KN (1993). Synthesis of 3, 4-cis-[3H] leucocyanidin and enzymatic reduction to catechin. Analytical Biochemistry 209(2):274-277.

Tsuda T, Yamaguchi M, Honda C, Moriguchi T (2004). Expression of anthocyanin biosynthesis genes in the skin of peach and nectarine fruit. Journal of the American Society for Horticultural Science 129(6):857862.

Wang H, Wang W, Zhang P, Pan Q, Zhan J, Huang W (2010). Gene transcript accumulation, tissue and subcellular localization of anthocyanidin synthase (ANS) in developing grape berries. Plant Science 179(1):103-113.
Wang H, Fan W, Li H, Yang J, Huang J, Zhang P (2013). Functiona characterization of dihydroflavonol-4-reductase in anthocyanin biosynthesis of purple sweet potato underlies the direct evidence of anthocyanins function against abiotic stresses. PLoS One 8(11):e78484.

Wei YZ, Hu FC, Hu GB (2011). Differential expression of anthocyanin biosynthetic genes in relation to anthocyanin accumulation in the pericarp of Litchichinensis Sonn. PLoS One 6(4):e19455.

Wisniewski M, Norelli J, Bassett C, Artlip T, Macarisin D (2011). Ectopic expression of a novel peach (Prunus persica) $\mathrm{CBF}$ transcription factor in apple (Malus $\times$ domestica) results in short-day induced dormancy and increased cold hardiness. Planta 233:971-983.

Xu F, Cheng H, Cai R, LiLL, ChangJ,Zhu J, ChengSY (2008). Molecular cloning and function analysis of an anthocyanidin synthase gene from Ginkgo biloba, and its expression in abiotic stress responses. Molecules and Cells 26(6):536-547.

Xu F, Ning Y, Zhang W, Liao Y, Li L, Cheng H, Cheng SY (2014). An R2R3-MYB transcription factor as a negative regulator of the flavonoid biosynthesis pathway in Ginkgo biloba. Functional Integrative Genomics 14(1):177-189.

Yan M, Liu X, Guan C, Chen X, Liu Z (2011). Cloning and expression analysis of an anthocyanidin synthase gene homolog from Brassica juncea. Molecular Breeding28(3):313-322.

Yan M, Ding S, Liu L, Yin X, Shu J (2014). Cloning and expression analysis of an anthocyanidin synthase gene homologue from Brassica carinata. Journal ofGenetics 93(2):513-516.

Yang YN, Zhao G, Yue WQ, Zhang SL, Gu C, Wu J (2013). Molecular cloning and gene expression differences of the anthocyanin biosynthesisrelated genes in the red/green skin color mutant of pear (Pyrus communisL.). Tree Genet Genomes 9(5):1351-1360.

YeJB, Yang XH, Chen QW, Xu F, Wang GY (2017). Promotive effects of 5-aminolevulinic acid on fruit quality and coloration of Prunus persica (L.) Batsch. Scientia Horticulturae 217:266-275.

Yoshida K, Toyama-Kato Y, Kameda K, Kondo T (2003). Sepal color variation of Hydrangea macrophylla and vacuolar $\mathrm{pH}$ measured with a proton-selective microelectrode. Plant and Cell Physiology 44(3):262268.

Zhang J, Han ZY, Tian J, Zhang X, Song TT, Yao YC (2015). The expression level of anthocyanidin synthase determines the anthocyanin content of crabapple (Malus sp.) petals. Acta Physiologiae Plantarum 37(6):109.

Zhou Y, Guo D, Li J, Cheng J, Zhou H, Gu C, Han YP (2013). Coordinated regulation of anthocyanin biosynthesis through photorespiration and temperature in peach (Prunus persica $\mathrm{f}$. atropurpurea). Tree Genetics and Genomes 9(1):265-278.

Zhou Y, Zhou H, Lin-Wang K, Vimolmangkang S, Espley RV, Wang L, Han Y (2014). Transcriptome analysis and transient transformation suggest an ancient duplicated MYB transcription factor as a candidate gene for leaf red coloration in peach. BMC Plant Biology 14(1):388.

Zhu L, Zhang X, Chang L, Wang A, Feng P, Han L (2014). Molecular cloning, prokaryotic expression and promoter analysis of squalene synthase gene from Schizochytrium limacinum. Applied Biochemistry and Microbiology 50(4):411-419. 